Case Report

\title{
An under-utilized opportunity: The wearable cardioverter-defibrillator (WCD)
}

\author{
Sachin Kumar Amruthlal Jain ${ }^{1}$, Alehegn Gelaye ${ }^{2 \star}$, Timothy R. Larsen ${ }^{2}$ and Shukri David ${ }^{1}$ \\ ${ }^{1}$ Department of Internal Medicine, Section of Cardiology, Providence Hospital and Medical Center, \\ Southfield, Michigan, USA. \\ ${ }^{2}$ Department of Internal Medicine, Providence Hospital and Medical Center, Southfield, Michigan, USA.
}

Accepted 18 December, 2012

\begin{abstract}
Sudden cardiac death is often precipitated by unstable ventricular arrhythmias. These arrhythmias are particularly amendable to defibrillation. The risk of these arrhythmias is highest immediately following an acute myocardial infarction, especially if there is impaired left ventricular function. Many patients with depressed left ventricular function receive an implantable cardioverter-defibrillator for prophylaxis against these lethal arrhythmias. The current guidelines recommend against implantable cardioverterdefibrillator implantation in the early period following myocardial infarction. This is because, given the time, arrhythmia risk typically decreases. The wearable cardioverter-defibrillator (WCD) can protect these vulnerable patients in the short term when arrhythmia risk is highest. Herein, we present a case of a 69 year old male who suffered a cardiac arrest four days after hospital discharge following an acute myocardial infarction.
\end{abstract}

Key words: Sudden cardiac death (SCD), defibrillation, implantable cardioverter-defibrillator (ICD), wearable cardioverter-defibrillator (WCD).

\section{INTRODUCTION}

Sudden cardiac death (SCD) is the leading cause of cardiovascular death in industrialized population and accounts for 300,000 to 400,000 deaths annually in the United States. It is estimated to account for up to $50 \%$ of all heart disease related deaths (Engelstein and Zipes, 1998). Despite advances in the treatment of acute coronary syndromes with early revascularization and effective secondary preventative therapies, the risk of sudden cardiac death remains high in the early period following myocardial infarction (MI). This is particularly true in the setting of severely reduced left ventricular function, reflected as a left ventricular ejection fraction (LVEF) less than 35\% (Solomon et al., 2005; Klein et al., 2010). In majority of the cases, SCD results from a ventricular arrhythmia, typically ventricular tachycardia or

*Corresponding author. E-mail: alehegn.gelaye@gmail.com. Tel: 248-242-1933. Fax: 248-849-3230. fibrillation (Huikuri et al., 2001). These arrhythmias are particularly amendable to defibrillation. Current guidelines, however, recommend against implantation of an implantable cardioverter-defibrillator (ICD) in the early period following an acute $\mathrm{MI}$ (Hohnloser et al., 2004; Zipes et al., 2006; Steinbeck et al., 2009; Epstein et al., 2008). We present a case of a 69 year-old man that died after sustaining a cardiac arrest 4 days after discharged home from a hospitalization for an acute MI.

\section{CASE REPORT}

A 69 year-old male presented with acute onset substernal chest tightness and heaviness that did not change with position or rest. It was associated with diaphoresis and shortness of breath. Past medical history was positive for hypertension and hyperlipidemia on treatment. Initial examination showed a heart rate of $73 / \mathrm{min}$, blood pressure of $123 / 65 \mathrm{mmHg}$, and respiratory rate of $16 / \mathrm{min}$ with oxygen saturation of $92 \%$ on $2 \mathrm{~L} / \mathrm{min}$ of oxygen. Cardiac examination revealed a normal S1 and S2 without murmurs or gallops. The point of maximal impulse was not displaced. The carotid upstrokes were 
Med. Pract. Rev.

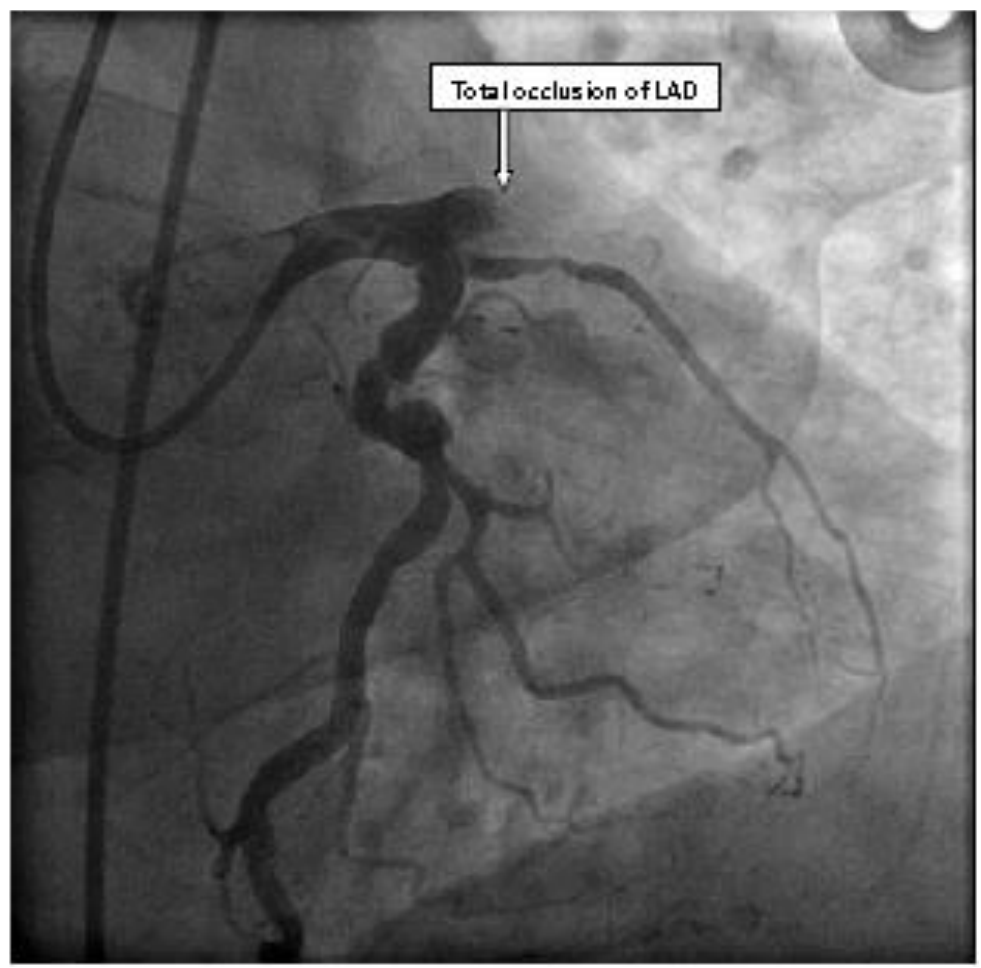

Figure 1. Coronary angiogram demonstrating total occlusion of the left anterior descending artery.
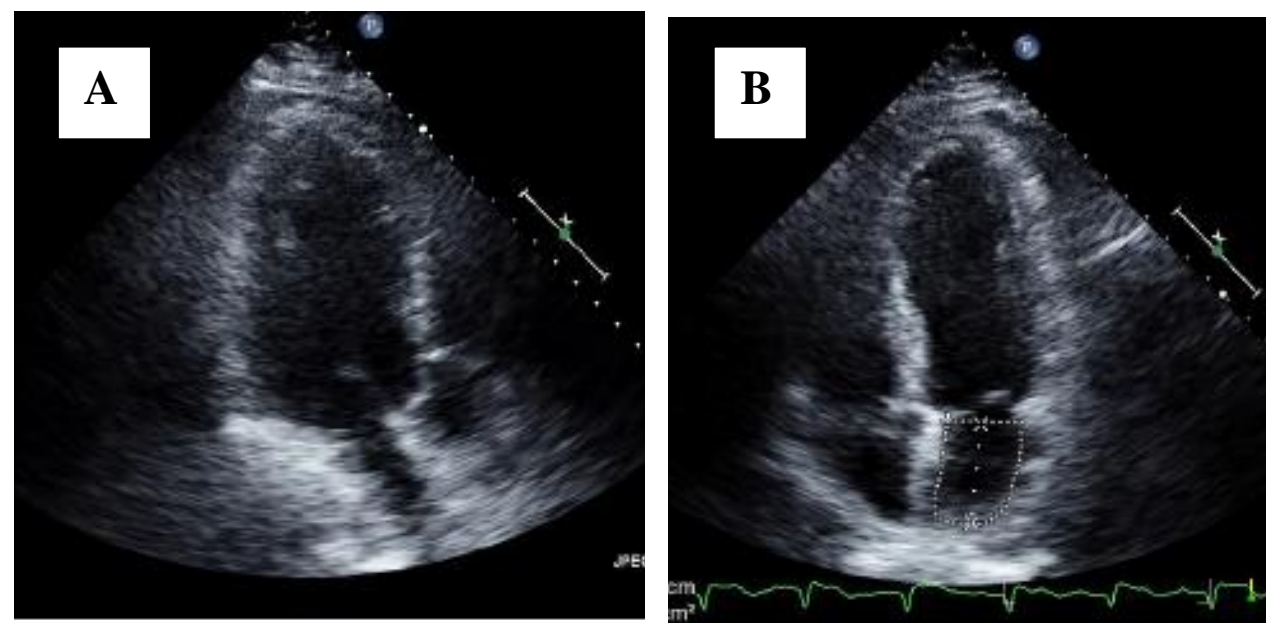

Figure 2. Echocardiogram after coronary revascularization demonstrating left ventricular dilatation with an estimated ejection fraction of $20 \%$ : panel A: diastole; panel B: systole.

normal bilaterally without carotid bruits. Peripheral pulses were palpable and symmetric. There was no peripheral edema. Lung fields were clear without wheezes, rhonchi, or rales. The remainder of the physical examination was unremarkable.

A 12-lead electrocardiogram revealed ST-segment elevation in leads V3 to V5, I and AVL with reciprocal ST depression in the inferior leads. He was given aspirin, nitroglycerin, clopidogrel, supplemental oxygen, intravenous heparin and was referred for emergent cardiac catheterization which revealed a total occlusion of the proximal segment of the left anterior descending artery (LAD)

\section{(Figure 1).}

Successful coronary intervention was performed with placement of three bare-metal stents to the proximal and mid LAD. The patient was then transferred to the cardiovascular intensive care unit in stable condition. He was started on daily aspirin, clopidogrel, carvedilol, lisinopril, and atorvastatin. Post catheterization 2D-echocardiogram showed mildly enlarged and eccentric left ventricular (LV) hypertrophy with severe global impairment in LV function. The estimated LV ejection fraction was $<20 \%$. The right heart chambers were normal in size with normal right ventricular function (Figure 2). 


\section{Sudden Cardiac Death Primary Prevention Protocols}

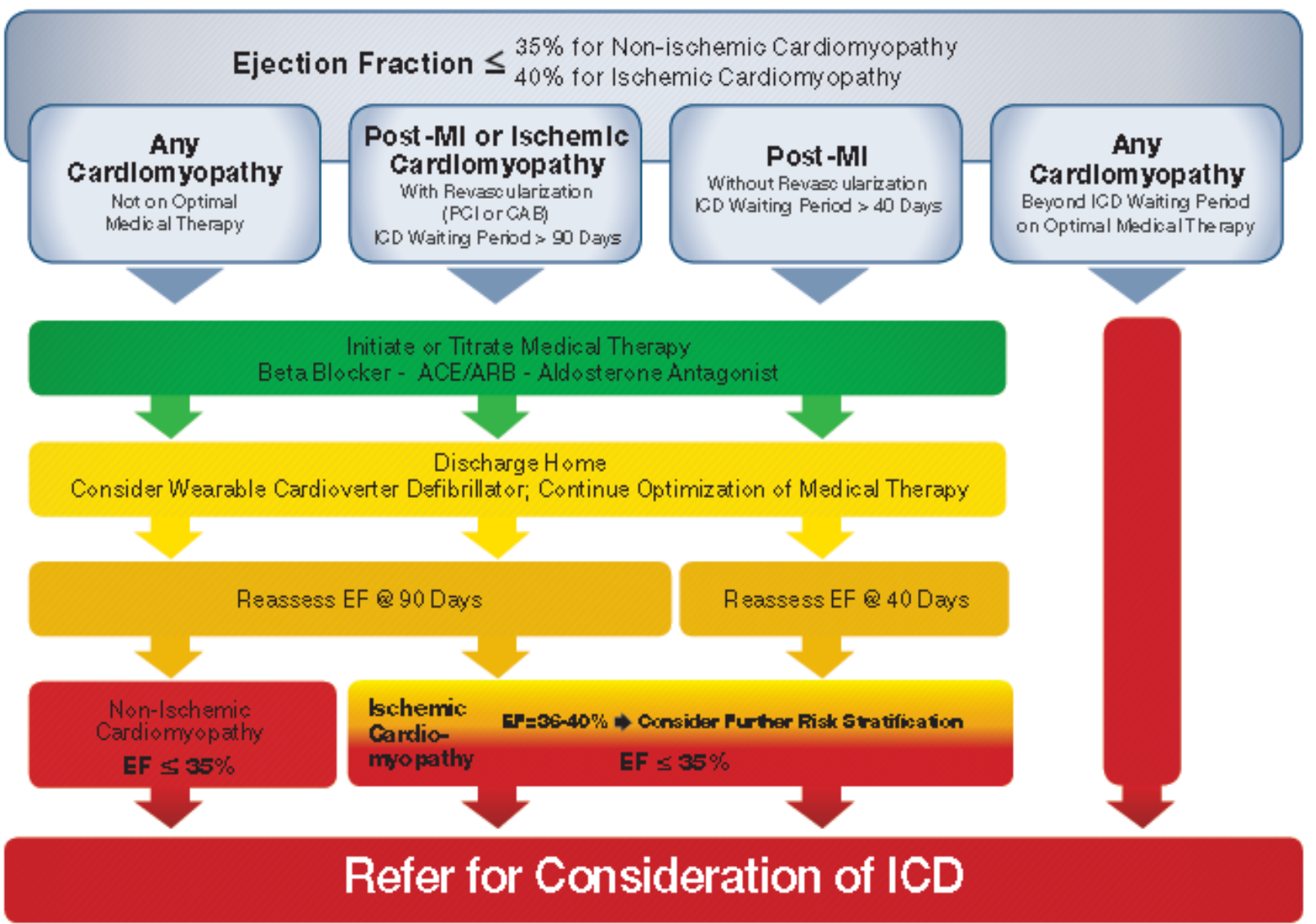

Figure 3. Heart Rhythm Society recommendations for the primary prevention of sudden cardiac death Source: Reproduced with permission from the Heart Rhythm Society.

On hospital day 6 , he was discharged home in stable condition with daily aspirin, clopidogrel, carvedilol, lisinopril and simvastatin. He was scheduled for repeat echocardiogram as an outpatient for evaluation of possible ICD implantation in the future. Four days after discharge, the patient suffered sudden cardiopulmonary arrest. Despite aggressive resuscitative efforts he expired.

\section{DISCUSSION}

Survivors of acute MI who have resultant left ventricular impairment are at high risk for ventricular arrhythmias and sudden cardiac death. Solomon et al. (2005) showed that the risk of SCD is highest in the first 30 days after myocardial infarction. Unstable ventricular arrhythmias, particularly ventricular tachycardia and fibrillation, account for the majority of SCD. The risk of death from these lethal arrhythmias, however, can be reduced by earlier implementation of appropriate preventive strategies. Several studies have demonstrated ICD devices to be effective in primary and secondary SCD prevention in high risk patients (Moss et al., 2002). Additionally, it has been established that ICDs significantly reduce SCD in the remote phase of infarction (after 40 days) if left ventricular function remains depressed (Moss et al., 1996).

Current guidelines require a minimum of 40 days (with optimal medical therapy) prior to implantation of an ICD after $\mathrm{Ml}$ and a minimum of 90 days after cardiac revascularization, regardless of LV function. This is because the risk of life threatening arrhythmias significantly decreases after the initial 40 days and with optimal medical therapy many patients will see improvements in LV function (and thus no longer qualify for an ICD). Patients with initially depressed LV function must therefore undergo follow up testing to establish persistence of LV dysfunction and thus need for a permanent ICD.

In patients with depressed LV function (LVEF $<35 \%$ ) in the acute phase following $\mathrm{MI}$ (within 40 days), a wearable cardioverter-defibrillator (WCD) is an effective approach for the prevention of SCD. This is particularly true if the patient experiences symptomatic heart failure, ventricular arrhythmias, or cardiac arrest prior to discharge. The Heart Rhythm Society recommends WCD, in addition to optimal medical therapy, for patients at the highest risk of SCD (Figure 3). WCD (also known as the Life Vest) is an 
external device capable of automatic detection and defibrillation of ventricular tachycardia or fibrillation. When worn properly, WCD appears to be as effective as an ICD for the termination of these deadly arrhythmias (Feldman et al., 2004) Both short term and long term survival was comparable to ICD (Chung et al., 2010). WCD can protect patients during the initial 40 day (or 90 day if revascularization took place) period after infarction when arrhythmic risk is highest and buy the time necessary to allow for improvements in LV function following optimal medical therapy. WCD can thus act as a bridge until a final decision for a permanent ICD can be made.

\section{Conclusion}

The case of this study reminds clinicians to identify patients at the highest risk of SCD and utilize all available options for the prevention of sudden cardiac death. WCD can prevent these vulnerable patients in the short term when the arrhythmia risk is highest. We would like to promote the implementation of guidelines set forth by the Heart Rhythm Society recommending the use of WCDs in high risk patients during the early period following an acute MI.

\section{REFERENCES}

Chung MK, Szymkiewicz SJ, Shao M, Zishiri E, Niebauer MJ, Lindsay BD, Tchou PJ (2010). Aggregate national experience with the wearable cardioverter-defibrillator: Event rates, compliance, and survival. J. Am. Coll. Cardiol. 56(3):194-203.

Engelstein E, Zipes D (1998). The heart, arteries and veins. McGrawHill, New York. pp. 1081-1112.

Epstein AE, DiMarco JP, Ellenbogen KA, Estes NA 3rd, Freedman RA, Gettes LS, Gillinov AM, Gregoratos G, Hammill SC, Hayes DL, Hlatky MA, Newby LK, Page RL, Schoenfeld MH, Silka MJ, Stevenson LW, Sweeney MO, Smith SC Jr, Jacobs AK, Adams CD, Anderson JL, Buller CE, Creager MA, Ettinger SM, Faxon DP, Halperin JL, Hiratzka LF, Hunt SA, Krumholz HM, Kushner FG, Lytle BW, Nishimura RA, Ornato JP, Page RL, Riegel B, Tarkington LG, Yancy CW (2008). ACC/AHA/HRS 2008 Guidelines for device-based therapy of cardiac rhythm abnormalities: A report of the ACC/AHA Task Force on Practice Guidelines. Circulation 117(21):e350-e408.
Feldman AM, Klein H, Tchou P, Murali S, Hall WJ, Mancini D, Boehmer J, Harvey M, Heilman MS, Szymkiewicz SJ, Moss AJ (2004). Use of a Wearable Defibrillator in Terminating Tachyarrhythmias in Patients at High Risk for Sudden Death. Pacing Clin. Electrophysiol. 27(1):4-9.

Hohnloser SH, Kuck KH, Dorian P, Roberts RS, Hampton JR, Hatala R, Fain E, Connolly SJ (2004). Prophylactic use of an implantable cardioverter-defibrillator after acute myocardial infarction. N. Engl. J. Med. 351(24):2481-2488.

Huikuri HV, Castellanos A, Myerburg RJ (2001). Sudden death due to cardiac arrhythmias. N. Engl. J. Med. 345(20):1473-1482.

Klein HU, Meltendorf U, Reek S, Smid J, Kuss S, Cygankiewicz I, Jons C, Szymkiewicz S, Buhtz F, Wollbrueck A, Zareba W, Moss AJ (2010). Bridging a temporary high risk of sudden arrhythmic death. Experience with the wearable cardioverter defibrillator (WCD). Pacing Clin. Electrophysiol. 33(3):353-367.

Moss AJ, Hall WJ, Cannom DS, Daubert JP, Higgins SL, Klein H, Levine JH, Saksena S, Waldo AL, Wilber D, Brown MW, Heo M (1996). Improved survival with an implanted defibrillator in patients with coronary disease at high risk for ventricular arrhythmia. N. Engl. J. Med. 335(26):1933-1940.

Moss AJ, Zareba W, Hall WJ, Klein H, Wilber DJ, Cannom DS, Daubert JP, Higgins SL, Brown MW, Andrews ML (2002). Prophylactic implantation of a defibrillator in patients with myocardial infarction and reduced ejection fraction. N. Engl. J. Med. 346(12):877-883.

Solomon SD, Zelenkofske S, McMurray JJ, Finn PV, Velazquez E, Ertl G, Harsanyi A, Rouleau JL, Maggioni A, Kober L, White H, Van de Werf F, Pieper K, Califf RM, Pfeffer MA (2005). Valsartan in Acute Myocardial Infarction Trial: Sudden death in patients with myocardial infarction and left ventricular dysfunction, heart failure, or both. $\mathrm{N}$ Engl. J. Med. 352:2581-2588.

Steinbeck G, Andresen D, Seidl K, Brachmann J, Hoffmann E, Wojciechowski D, Kornacewicz-Jach Z, Sredniawa B, Lupkovics G, Hofgärtner $F$, Lubinski $A$, Rosenqvist $M$, Habets $A$, Wegscheider $K$, Senges J (2009). Defibrillator implantation early after myocardial infarction. N. Engl. J. Med. 361(15):1427-1436.

Zipes DP, Camm AJ, Borggrefe M, Buxton AE, Chaitman B, Fromer M, Gregoratos G, Klein G, Moss AJ, Myerburg RJ, Priori SG, Quinones MA, Roden DM, Silka MJ, Tracy C (2006). ACC/AHA/ESC 2006 guidelines for management of patients with ventricular arrhythmias and the prevention of sudden cardiac death: a report of the American College of Cardiology/American Heart Association Task Force and the European Society of Cardiology Committee for Practice Guidelines (Writing Committee to Develop Guidelines for Management of Patients With Ventricular Arrhythmias and the Prevention of Sudden Cardiac Death). J. Am. Coll. Cardiol. 48(5):e247-e346. 